Annales Geophysicae (2001) 19: 925-931 C European Geophysical Society 2001

\title{
Typhoon 9707 observations with the MU radar and L-band boundary layer radar
}

\author{
M. Teshiba ${ }^{1}$, H. Hashiguchi ${ }^{1}$, S. Fukao ${ }^{1}$, and Y. Shibagaki ${ }^{2}$ \\ ${ }^{1}$ Radio Science Center for Space and Atmosphere, Kyoto University, Uji, Kyoto 611-0011, Japan \\ ${ }^{2}$ Osaka Electro-Communication University, Neyagawa, Osaka 572-8530, Japan
}

Received: 20 October 2000 - Revised: 8 June 2001 - Accepted: 27 July 2001

\begin{abstract}
Typhoon 9707 (Opal) was observed with the VHF-band Middle and Upper atmosphere (MU) radar, an L-band boundary layer radar (BLR), and a vertical-pointing C-band meteorological radar at the Shigaraki MU Observatory in Shiga prefecture, Japan on 20 June 1997. The typhoon center passed about $80 \mathrm{~km}$ southeast from the radar site. Mesoscale precipitating clouds developed due to warmmoist airmass transport from the typhoon, and passed over the MU radar site with easterly or southeasterly winds. We primarily present the wind behavior including the vertical component which a conventional meteorological Doppler radar cannot directly observe, and discuss the relationship between the wind behavior of the typhoon and the precipitating system. To investigate the dynamic structure of the typhoon, the observed wind was divided into radial and tangential wind components under the assumption that the typhoon had an axi-symmetric structure. Altitude range of outflow ascended from $1-3 \mathrm{~km}$ to $2-10 \mathrm{~km}$ with increasing distance (within 80-260 km range) from the typhoon center, and inflow was observed above and below the outflow. Outflow and inflow were associated with updraft and downdraft, respectively. In the tangential wind, the maximum speed of counterclockwise winds was confirmed at $1-2 \mathrm{~km}$ altitudes. Based on the vertical velocity and the reflectivity obtained with the MU radar and the C-band meteorological radar, respectively, precipitating clouds, accompanied by the wind behavior of the typhoon, were classified into stratiform and convective precipitating clouds. In the stratiform precipitating clouds, a vertical shear of radial wind and the maximum speed of counterclockwise wind were observed. There was a strong reflectivity layer called a 'bright band' around the $4.2 \mathrm{~km}$ altitude. We confirmed strong updrafts and downdrafts below and above it, respectively, and the existence of a relatively dry layer around the bright band level from radiosonde soundings. In the convective precipitating clouds,
\end{abstract}

Correspondence to: H. Hashiguchi

(hasiguti@kurasc.kyoto-u.ac.jp) the regions of strong and weak reflectivities were well associated with those of updraft and downdraft, respectively.

Key words. Meteorology and atmospheric dynamics (mesoscale meteorology; precipitation) Radio science (remote sensing)

\section{Introduction}

Typhoons have been observed with various instruments in Japan. Ishihara et al. (1986) examined the wind fields and the internal structure of the rainband of Typhoon 8305 using the ground-based Doppler radar and showed that the convergence between the low-level warm inflow and the descending rear flow was associated with the relatively cold air. Sakakibara et al. (1985) showed that the structure of the rain band in the extratropical transition of the typhoon was partially similar to that of a squall line at mid-latitudes. Tabata et al. (1992) showed the structure of spiral rain bands (outer and inner rain bands) of Typhoon 8514. Shimazu (1997) showed that two types of rain bands, wide, slow-moving and narrow, fast-moving, were characterized by stratiform precipitation in which low-level shallow convective cells were embedded.

The radar observations in the studies mentioned above are limited in existence to the region of the precipitation. The MU (Middle and Upper atmosphere) radar (Fukao et al., $1985 \mathrm{a}, \mathrm{b})$ is one of the most powerful instruments for typhoon observations, since it can observe height profiles of the wind field, including the vertical motion in any weather conditions. The MU radar is a $46.5 \mathrm{MHz}$ monostatic Doppler radar with an active phased-array antenna of $103 \mathrm{~m}$ in diameter and with $1 \mathrm{MW}$ peak output power, located at Shigaraki, Shiga prefecture, Japan $\left(34.85^{\circ} \mathrm{N}, 136.10^{\circ} \mathrm{E} ; 375 \mathrm{~m}\right.$ above mean sea level). Sato et al. (1991) continuously observed Typhoon 8719 with the MU radar and showed short-period wind fluctuations associated with the typhoon. Sato (1993) studied small-scale wind disturbances associated with this 


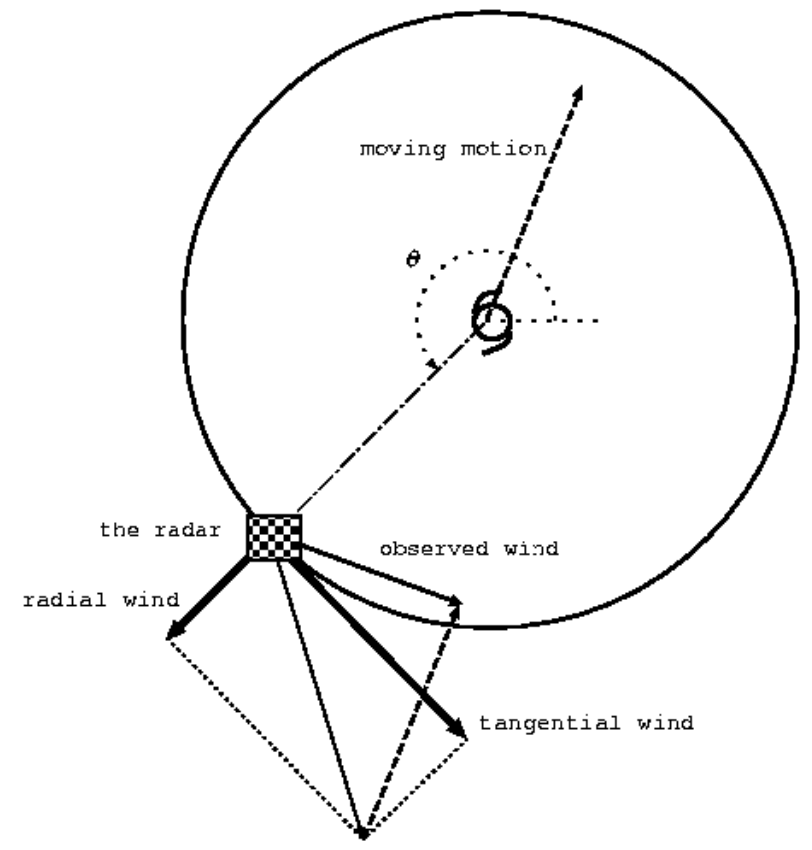

Fig. 1. Schematic illustration of analysis method based on an assumption of an axi-symmetrical structure of the typhoon. Rectangle shows radar position. Thin solid, broken, and thick solid vectors indicate horizontal wind observed by radar, moving speed of the typhoon center, and tangential and radial components, respectively.

typhoon and showed significant differences in its statistical characteristics before and after the typhoon passage.

We successfully observed Typhoon 9707 (Opal) with the MU radar on 20 June 1997. The MU radar can continuously observe height profiles of the wind field in the troposphere and lower stratosphere with the high time and height resolutions of $3 \mathrm{~min}$ and $150 \mathrm{~m}$, respectively. It can observe all three components of the wind velocity vector, including the vertical velocity and the falling speed of precipitating particles (e.g. Wakasugi et al., 1986; Sato et al., 1991), while meteorological Doppler radars cannot observe the vertical wind component. Therefore, we examine the behavior of the vertical wind.

The lowest observable height of the MU radar is, however, about $2 \mathrm{~km}$, due to the system limitation. To examine the lower part of the troposphere, we used an L-band boundary layer radar (BLR) which is installed at the MU radar site. The BLR is a $1357.5 \mathrm{MHz}$ monostatic Doppler radar with a phased-array antenna and with $1.1 \mathrm{~kW}$ peak output power, and has time and height resolutions of about $1 \mathrm{~min}$ and 100 $\mathrm{m}$, respectively. Using both radars, we can obtain the continuous height profiles from the $800 \mathrm{~m}$ to about the $20 \mathrm{~km}$ altitude. We also operated a C-band meteorological radar installed at the same site to investigate the vertical structure of precipitating clouds. It is a vertical-pointing radar with the transmitting frequency of $5.3 \mathrm{GHz}$ and with the peak output power of $40 \mathrm{~kW}$ (Fukao et al., 1985c). Specifications of these radars are summarized in Table 1.

Since it is impossible to transport the MU radar to another place, the opportunity to observe typhoons is rare. First, we could successfully first observe the typhoon by using both of MU radar and the L-band BLR in this study. The main objectives of this paper are to describe the wind behavior in the troposphere, including the boundary layer obtained by both radars, and to investigate the relationship between the vertical wind behavior and the structure of the typhoon.

\section{Analysis method}

First, by connecting the data obtained from the MU radar and the BLR at the $3.1 \mathrm{~km}$ altitude, we made a complete tropospheric dataset. Atmospheric radars like the MU radar and the BLR can obtain only the temporal variation of the vertical profiles of the wind velocities over the radar, but cannot directly observe the spatial structure of the typhoon. If we assume, however, that the structure of the typhoon is persistent during the period of observation, the time series of data can be transformed into one cross section of the typhoon structure. The locations of the typhoon are estimated from spline interpolation of locations reported every 1-6 hours by Japan Meteorological Agency (JMA).

To examine the winds associated with the typhoon structure, the environmental wind (approximated by the mean translational velocity of the typhoon center) is subtracted from the observed one. It is also assumed that the translational velocity of the typhoon center does not change in height. The subtracted wind is divided into radial and tangential wind components under the assumption that the typhoon has an axi-symmetric structure (see Fig. 1).

We examined the appropriateness of the above assumptions from the geopotential field at the $500 \mathrm{hPa}$ level, from the surface pressure field, and from the infrared (IR) imagery of the Geostationary Meteorological Satellite (GMS). The typhoon locations at $500 \mathrm{hPa}$ and on the surface are almost the same, and the cloud distribution associated with the typhoon has an axi-symmetric structure around the center axis. Therefore, it is concluded that the above assumptions are appropriate.

Figure 2 shows the horizontal distribution of a 1-hour precipitation obtained by the C-band meteorological radar network of JMA at the $2 \mathrm{~km}$ altitude for $0500-1000$ LT on 20 June 1997, when the typhoon center was located at about 220,148 , and $82 \mathrm{~km}$ distance from the MU radar site, respectively. The rain bands associated with the typhoon and affected by the Kii Mountains, which are located around $20 \mathrm{~km}$ southeast of the radar site, were observed. Willoughby et al. (1984) studied the rain bands corresponding to typhoons. Typhoons have several rain bands associated with their structures, such as principal bands, secondary bands, connecting bands with principal and secondary band, and eye wall (see Fig. 18 of Willoughby et al., 1984). In our case, the 'connecting band' was located around the stationary rain band until the typhoon passed over the radar site, while the 'principal band' was not clearly seen around the typhoon. Since the precipitating clouds passing over the radar site were a part 


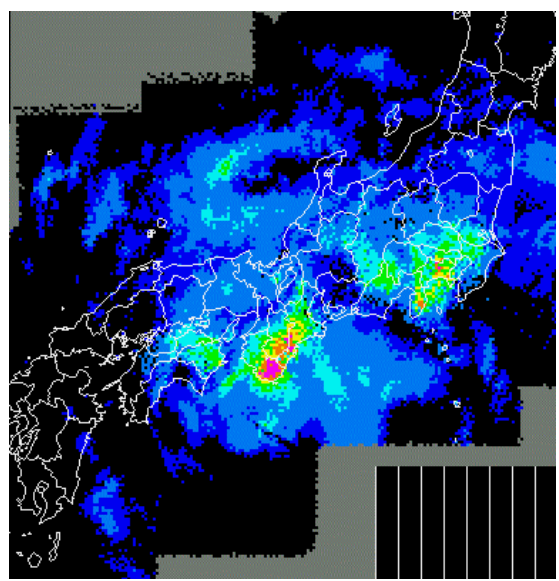

(a)

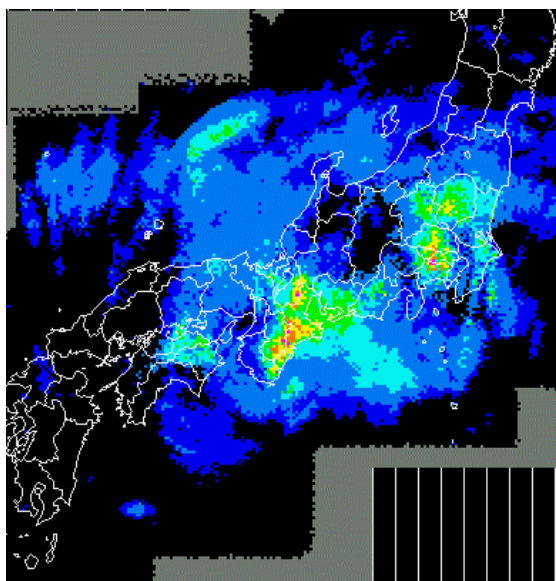

(b)

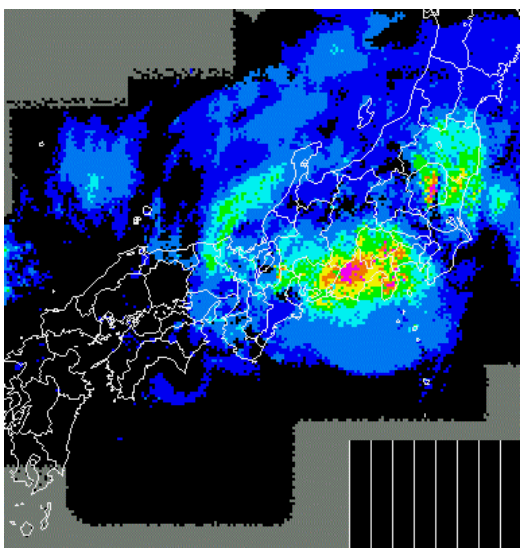

(c)

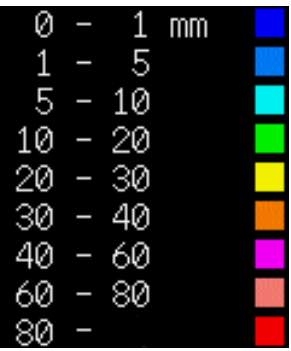

Fig. 2. Horizontal distributions of the amount of rainfall for (a) 05-06 LT, (b) 07-08 LT, and (c) 09-10 LT on 20 June 1997.

of the stationary rain band along the mountainous region, we suppose that the convective clouds observed over the radar site were not associated with the typhoon structure, but were generated by orographic effects.

We have classified precipitating clouds into three types: stratiform, convective, and mixed stratiform-convective clouds, based on the vertical motion observed by the MU radar and the reflectivity observed by the C-band meteorological radar. If there are no characteristics of a bright band, it is classified as 'convective cloud'. If strong echoes exist around the bright band level, we classify this precipitating cloud as 'stratiform precipitating cloud', except for the type of precipitating cloud where the vertical change in the vertical wind component is small. This type is classified as 'mixed stratiform-convective cloud'.

\section{Features of wind structure}

Figure 3 shows the path of Typhoon 9707. The typhoon approached from south of the Japan Islands, passed over the closest region of about $80 \mathrm{~km}$ southeast from the radar site at 1020 LT on 20 June, and landed in Aichi prefecture around 1100 LT. Figures 4 and 5 show temporal variations of the surface meteorological data obtained at the radar site. The pres- sure and temperature were decreasing and increasing, respectively, associated with the approach of the typhoon. Minimum pressure and the drastic change in the wind direction appeared around $1020 \mathrm{LT}$, when the typhoon was closest to the radar site.

Figure 6 shows the time-height cross section of the horizontal wind component observed with the MU radar and the BLR. The easterly or southeasterly winds are observed between about $1 \mathrm{~km}$ and $10 \mathrm{~km}$ until the passage of the typhoon. Since the mountainous region of about $1 \mathrm{~km}$ in height is located from east to southeast of the MU radar site (see Fig. 7), as the typhoon passed near the radar site, mesoscale precipitating clouds developed due to warm-moist airmass transport from the typhoon and passed over the MU radar site.

Figure 8 shows the radius-height cross section of vertical velocity obtained with the MU radar and reflectivity obtained with the vertical-pointing C-band meteorological radar before the passage of the typhoon center. We only plot the MU radar data in Fig. 8(a), since the BLR cannot obtain vertical velocity information in precipitation due to its high sensitivity to precipitation. Of course, the BLR can observe horizontal winds even in precipitation (Wakasugi et al. 1986).

We can divide these into three regions (Regions A, B, and $\mathrm{C})$, according to cloud types. Regions A, B, and C corre- 
Table 1. Specifications of the MU radar, the L-band BLR, and the C-band radar

\begin{tabular}{|c|c|c|c|}
\hline & MU Radar & L-band BLR & C-band Radar \\
\hline Location: & \multicolumn{3}{|c|}{ Shigaraki, Shiga, Japan $\left(34.85^{\circ} \mathrm{N}, 136.10^{\circ} \mathrm{E}\right)$} \\
\hline Operating frequency: & $46.5 \mathrm{MHz}$ & $1357.5 \mathrm{MHz}$ & $5265 \mathrm{MHz}$ \\
\hline Antenna: & \multicolumn{2}{|c|}{ Phased array antenna } & Parabolic antenna \\
\hline Aperture: & $8,330 \mathrm{~m}^{2}$ & $5.9 \mathrm{~m}^{2}$ & $7.0 \mathrm{~m}^{2}$ \\
\hline Beam width: & $3.6^{\circ}$ & $4.1^{\circ}$ & $1.0^{\circ}$ \\
\hline Beam directions: & \multicolumn{2}{|c|}{$\begin{aligned}(\mathrm{Az}, \mathrm{Ze})= & (0,0),\left(0,10^{\circ}\right),\left(90^{\circ}, 10^{\circ}\right) \\
& \left(180^{\circ}, 10^{\circ}\right),\left(270^{\circ}, 10^{\circ}\right)\end{aligned}$} & Vertical fixed \\
\hline Transmitter: & \multicolumn{2}{|c|}{ Solid-state amplifiers } & Magnetron \\
\hline Peak power: & $1 \mathrm{MW}$ & $1.1 \mathrm{~kW}$ & $40 \mathrm{~kW}$ \\
\hline Pulse width: & $1 \mu \mathrm{s}$ & $0.67 \mu \mathrm{s}$ & $1.1 \mu \mathrm{s}$ \\
\hline IPP: & $400 \mu \mathrm{s}$ & $50 \mu \mathrm{s}$ & $6.1 \mathrm{~ms}$ \\
\hline
\end{tabular}

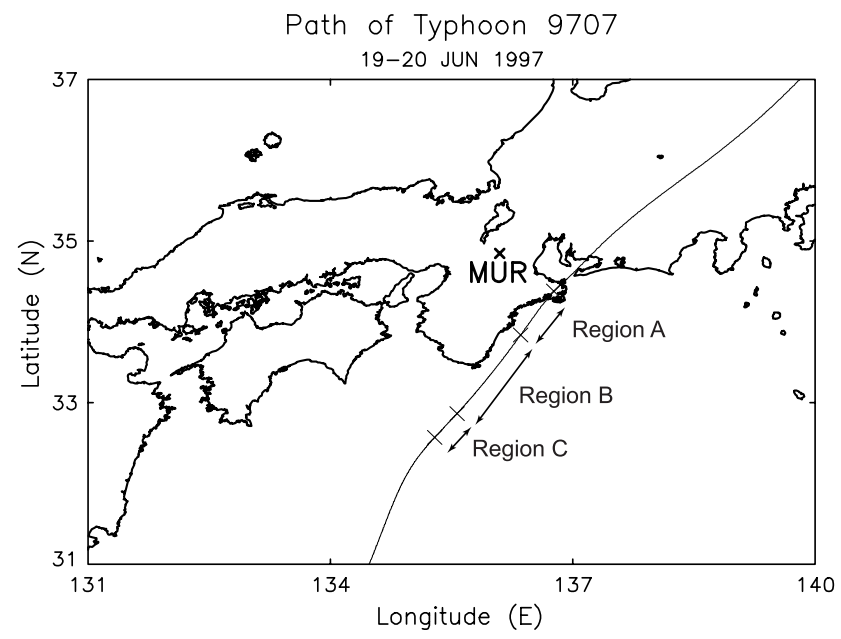

Fig. 3. Path of Typhoon 9707 calculated from the spline interpolation applied with the locations reported by JMA. A cross sign $(x)$ indicates the location of the MU radar.

spond to the distances of $80-120 \mathrm{~km}, 120-225 \mathrm{~km}$, and 225 $260 \mathrm{~km}$ from the typhoon center, respectively. The cloud type in Region A is classified as the stratiform precipitating cloud, because the bright band exists at the $4.2 \mathrm{~km}$ altitude. As Marks and Houze (1987) here already shown, these stratiform precipitating clouds are situated outside the eye wall. The cloud type in Region B is the mixed stratiformconvective cloud, because the bright band exists around the $4.2 \mathrm{~km}$ altitude and the vertical change in the vertical wind component is small. Tabata et al. (1992) studied the structure of the typhoon passing near the southeast coast of Japan. In their case, stratiform precipitating clouds were observed and there was no orographic effect because there were few mountains located there. Therefore, stratiform precipitating clouds in Region B are associated with the characteristic structure of the typhoon. On the other hand, convective clouds seem to be affected by both the characteristic structure of the typhoon and the orographic effect due to the mountains in the southeast side of the radar site, since the easterly winds are observed in the lower troposphere of Region B. The cloud type in Region $\mathrm{C}$ is convective cloud, because the bright band does not exist and updrafts and downdrafts are alternately observed at a distance from the typhoon center.

Figure 9 shows the radius-height cross section of radial and tangential winds obtained by the MU radar and the BLR. We describe the characteristics of Typhoon 9707 in each region in the following subsections.

\subsection{Features in stratiform precipitating cloud region}

In Region A (at the distance of $80-120 \mathrm{~km}$ ), inflow below $1 \mathrm{~km}$ and above the $3 \mathrm{~km}$ altitude, and outflow at the altitude range of $1-3 \mathrm{~km}$ are observed. The maximum counterclockwise wind of about $40 \mathrm{~m} / \mathrm{s}$ appears around the $1 \mathrm{~km}$ altitude. The vertical shear of counterclockwise winds is seen around the $2 \mathrm{~km}$ altitude. Strong updrafts around $2 \mathrm{~km}$, weak downdrafts at $3-7 \mathrm{~km}$, and updrafts above the $7 \mathrm{~km}$ altitude are observed. The vertical shear of radial winds seems to be associated with that of vertical winds at the $2-3 \mathrm{~km}$ altitudes.

\subsection{Features in mixed stratiform-convective precipitating cloud region}

At a distance of $120-170 \mathrm{~km}$ from the typhoon center, weak inflow is observed above and below the outflow. The maximum speed of counterclockwise winds is obtained around the $1.5 \mathrm{~km}$ altitude. Updrafts extend below about the $4 \mathrm{~km}$ altitude and sometimes extend up to the $6 \mathrm{~km}$ altitude. Inflow and outflow are almost associated with the updrafts and downdrafts, respectively. There exists the bright band at the $4.2 \mathrm{~km}$ altitude. It is considered that there is severe convection and that the precipitating clouds are in the developing stage. Figure 10 shows the temperature and humidity profiles obtained by radiosonde soundings launched at 0531 LT $(\sim 240 \mathrm{~km}$ distance from the typhoon center) and $0826 \mathrm{LT}$ $(\sim 130 \mathrm{~km}$ distance) on 20 June. 
20-JUN-1997 04h-20-JUN-1997 11h Tz= $9.0 \lambda=136.10 \quad b=34.85 \mathrm{z}=385$
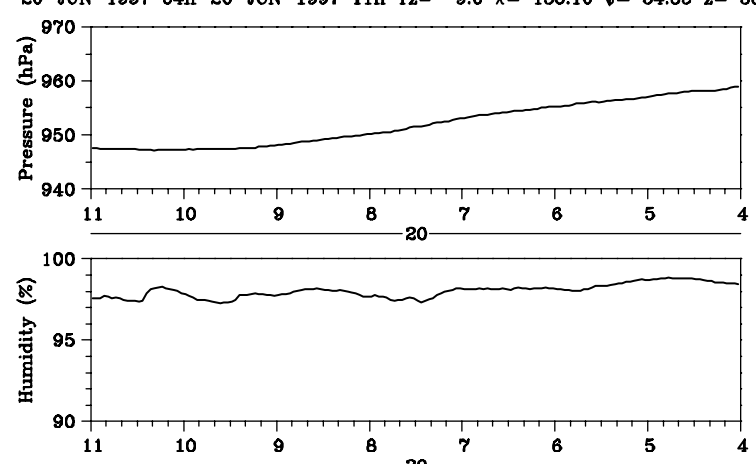

JUN

4 JUN 97
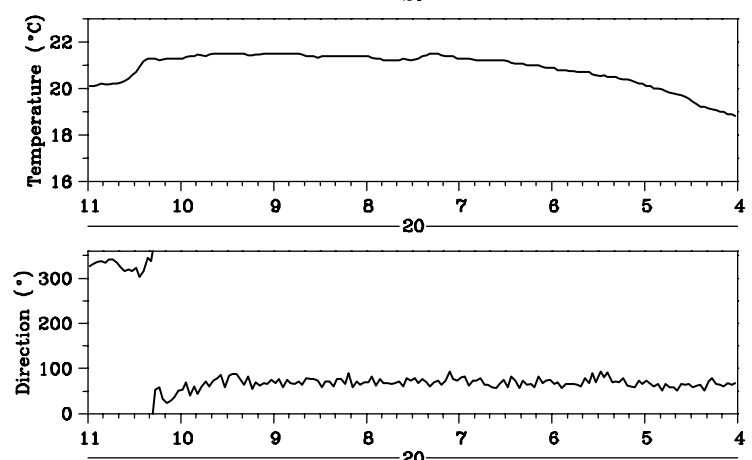

(d)

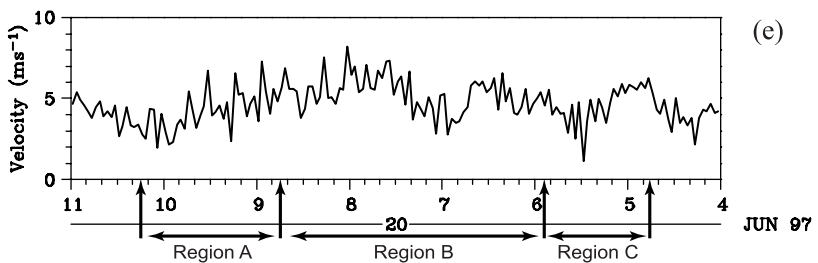

Fig. 4. Temporal variations of (a) pressure, (b) humidity, (c) temperature, (d) wind direction, and (e) wind speed on the ground at the MU radar site during 0400-1100 LT on 20 June 1997.

A relatively dry layer appears around the $4.2 \mathrm{~km}$ altitude, which corresponds to the change in the vertical wind with the divergence. At a distance of $170-200 \mathrm{~km}$ from the typhoon center, weak inflow is also observed above and below the outflow. The maximum speed of the counterclockwise winds is obtained around the $2 \mathrm{~km}$ altitude. The magnitudes of the maximum counterclockwise winds, however, become smaller with increasing distance from the typhoon center. Updrafts extend from $2.5 \mathrm{~km}$ to $7 \mathrm{~km}$ and there are alternately updrafts and downdrafts in distance. In particular, strong updrafts are observed around the bright band level at the $195 \mathrm{~km}$ distance. Above the $7 \mathrm{~km}$ altitude, vertical velocity is weak. A vertical shear of counterclockwise winds is associated with outflow. At a distance of $200-225 \mathrm{~km}$ from the typhoon center, there is inflow below $1.5 \mathrm{~km}$ and above $8.5 \mathrm{~km}$, and outflow at the $1.5-8.5 \mathrm{~km}$ altitudes. The magnitude of counter-clockwise winds is smaller than that at the distance of $80-200 \mathrm{~km}$. There are downdrafts below the $8 \mathrm{~km}$ altitude; thus, it is considered that the precipitating cloud is in the decay stage. The vertical shear of radial winds is accompanied by that of the vertical winds around the $8 \mathrm{~km}$ altitude.

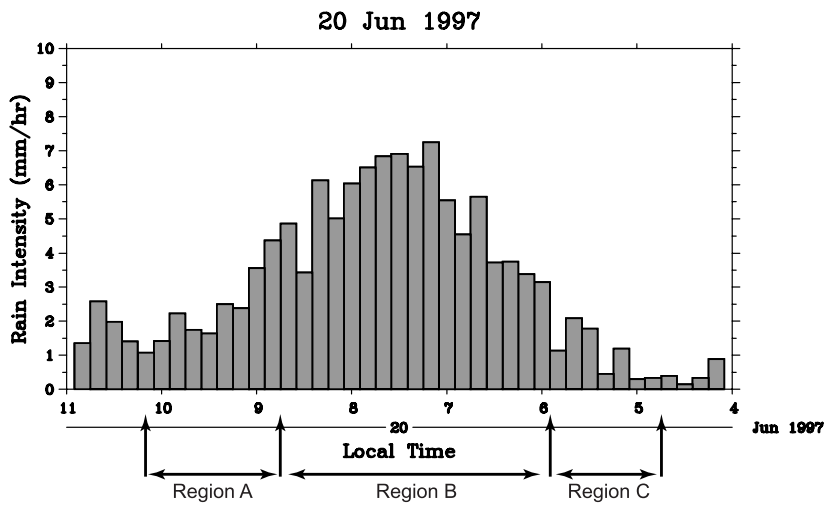

Fig. 5. Temporal variations of rain intensity on the ground at the MU radar site during 0400-1100 LT on 20 June 1997.

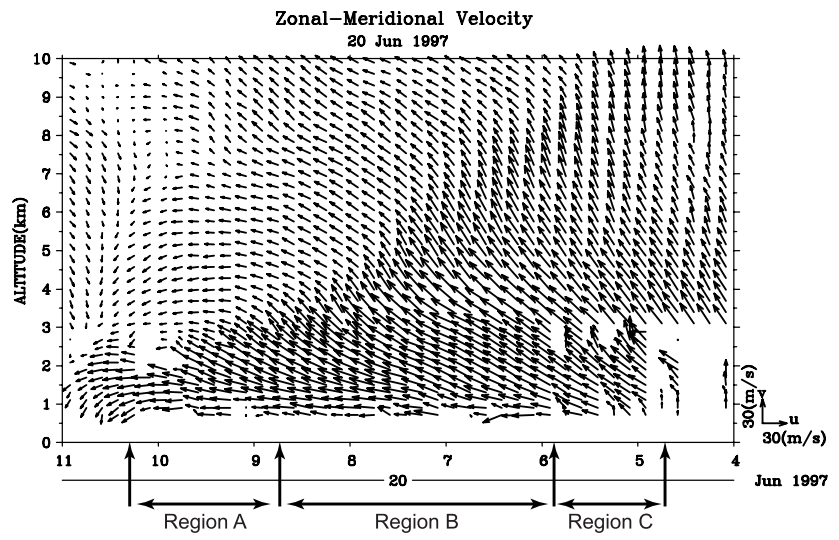

Fig. 6. Time-height cross section of horizontal wind component observed with the MU radar and the L-band BLR at an interval of 9 min during 0400-1100 LT on 20 June 1997. The height interval of the MU radar and the BLR is $150 \mathrm{~m}$ and $100 \mathrm{~m}$, respectively.

\subsection{Features in convective precipitating cloud region}

In Region C (at the distance of $225-260 \mathrm{~km}$ ), inflow and the counterclockwise winds with magnitudes of more than $25 \mathrm{~m} / \mathrm{s}$ are observed below the $2 \mathrm{~km}$ altitude. Updrafts and downdrafts alternately appear with increasing distance from the typhoon center, while the updrafts are weaker than those at the distance of $80-225 \mathrm{~km}$. Therefore, the precipitating clouds are not in the developing stage.

\section{Concluding remarks}

We simultaneously observed Typhoon 9707 with the MU radar, the BLR, and the vertical pointing C-band meteorological radar. Outflow and inflow in the radial wind were associated with updraft and downdraft, respectively. In the tangential wind, the maximum speed was observed in the altitude range of $1-2 \mathrm{~km}$ and the wind speed decreased by increasing altitude. Precipitating clouds, accompanied with the wind behaviors of the typhoon, were classified into strat- 


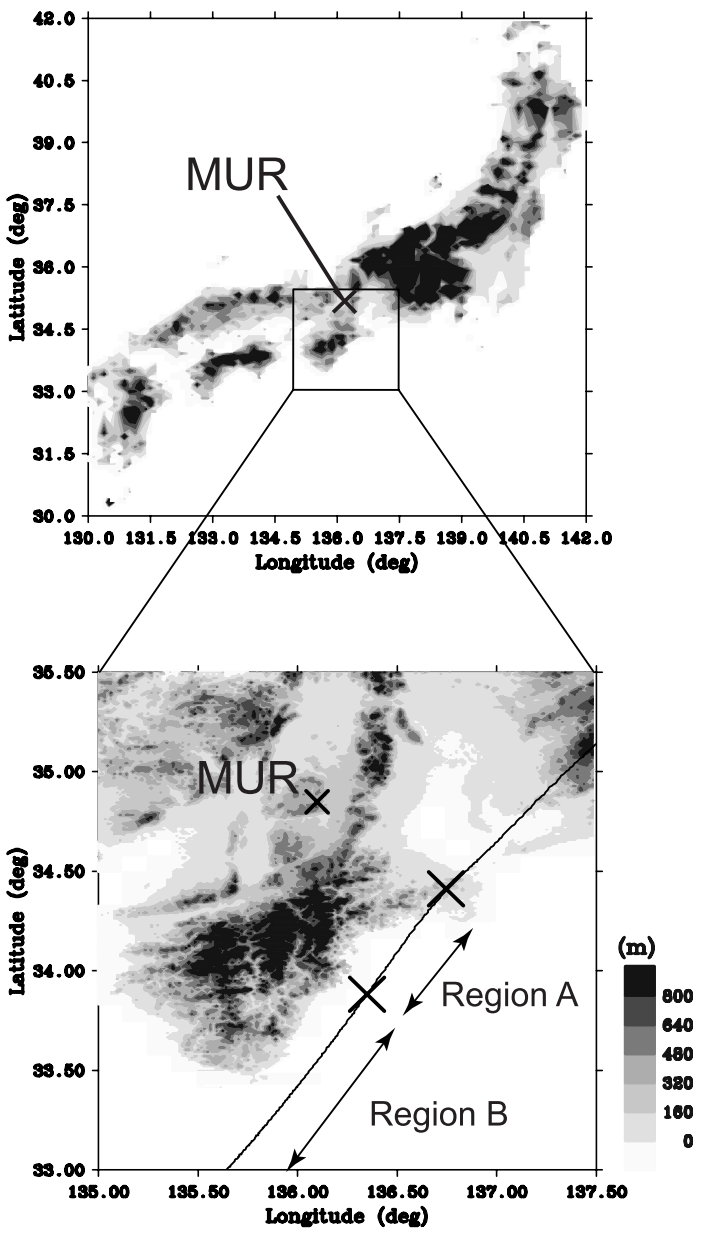

Fig. 7. Topographical map around the MU radar site.

iform, convective, and mixed stratiform-convective precipitating clouds by using the vertical velocity and the reflectivity obtained from the MU radar and the C-band radar, respectively. In the stratiform precipitating cloud, a vertical shear of radial winds and the maximum speed of counterclockwise winds were observed. There was a prominent bright band around the $4 \mathrm{~km}$ altitude, which corresponds to a relatively dry layer. Strong updrafts and downdrafts were seen above and below it, respectively. In the convective precipitating cloud, the regions of strong and weak reflectivities were well associated with those of updraft and downdraft, respectively.

Acknowledgements. The authors thank Prof. M. D. Yamanaka of Kobe University for his helpful comments. They also thank Mr. I. Ougisawa for the data analysis and comments. We thank Mr. Gernot Hassenpflug for his careful reading of the original manuscript. The MU radar belongs to and is operated by the Radio Science Center for Space and Atmosphere, Kyoto University.

Topical Editor J.-P. Duvel thanks M. Larsen and A. R. Hansen for their help in evaluating this paper.
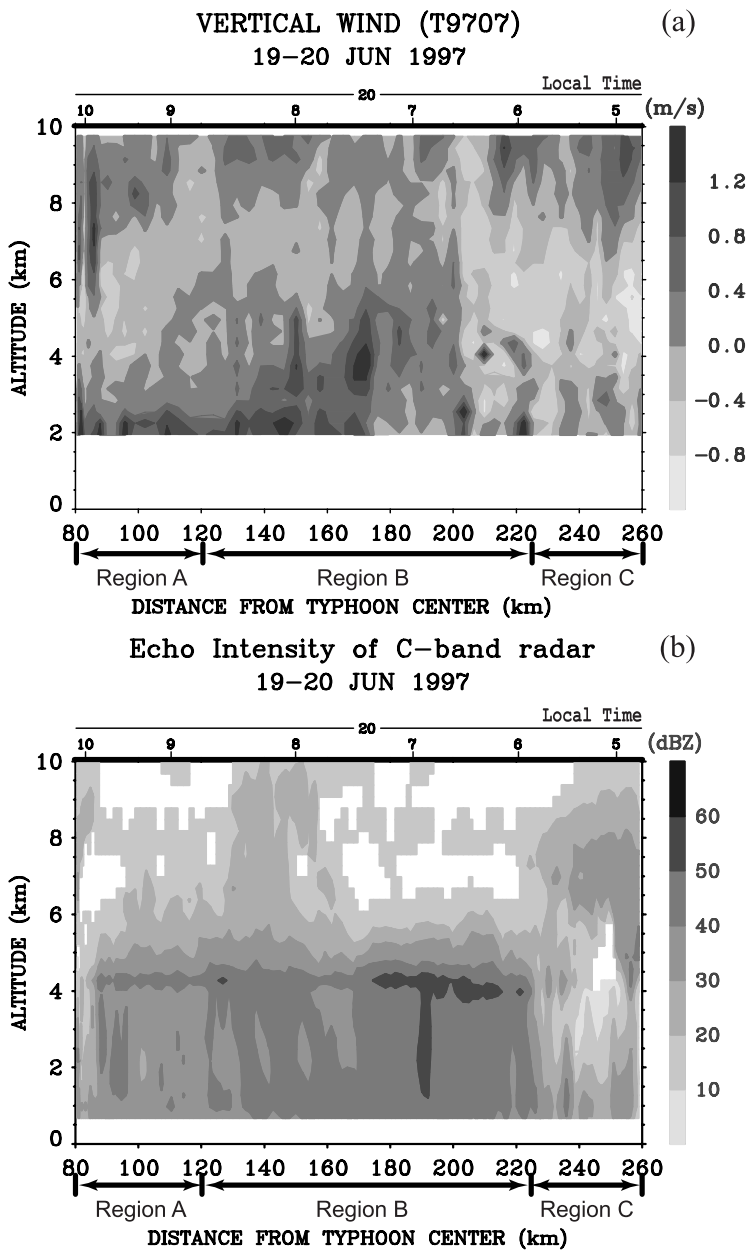

Fig. 8. Radius-height cross section of (a) vertical velocity obtained with the MU radar and (b) reflectivity obtained with the C-band meteorological radar before the passage of the typhoon center at an interval of $6 \mathrm{~min}$. The height interval of the MU radar and the C-band radar is $150 \mathrm{~m}$ and $300 \mathrm{~m}$, respectively.

\section{References}

Fukao, S., Sato, T., Tsuda, T., Kato, S., Wakasugi, K., and Makihira, T., The MU radar with an active phased array system: 1. Antenna and power amplifiers, Radio Sci., 20, 1155-1168, 1985a.

Fukao, S., Tsuda, T., Sato, T., Kato, S., Wakasugi, K., and Makihira, T., The MU radar with an active phased array system: 2. In-house equipment, Radio Sci., 20, 1169-1176, 1985b.

Fukao, S., Wakasugi, K., Sato, T., Tsuda, T., Kimura, I., Takeuchi, N., Matsuo, M., and Kato, S., Simultaneous observation of precipitating atmosphere by $\mathrm{VHF}$ band and $\mathrm{C} / \mathrm{Ku}$ band radars, Radio Sci., 20, 622-630, 1985c.

Ishihara, M., Yanagisawa, Z., Sakakibara, H., Matsuura, K., and Aoyagi, J., Structure of a typhoon rainband observed by two Doppler radars, J. Meteor. Soc., Japan, 64, 923-939, 1986.

Marks, D. F. Jr., and House, R. A., Jr., Inner core structure of hurricane Alicia from airborne Doppler radar observation, J. Atmos. Sci., 44, 1296-1317, 1987.

Sakakibara, H., Ishihara, M., and Yanagisawa, Z., Structure of a typhoon rainstorm in the middle latitudes observed by Doppler radar, J. Meteor. Soc., Japan, 63, 901-922, 1985. 


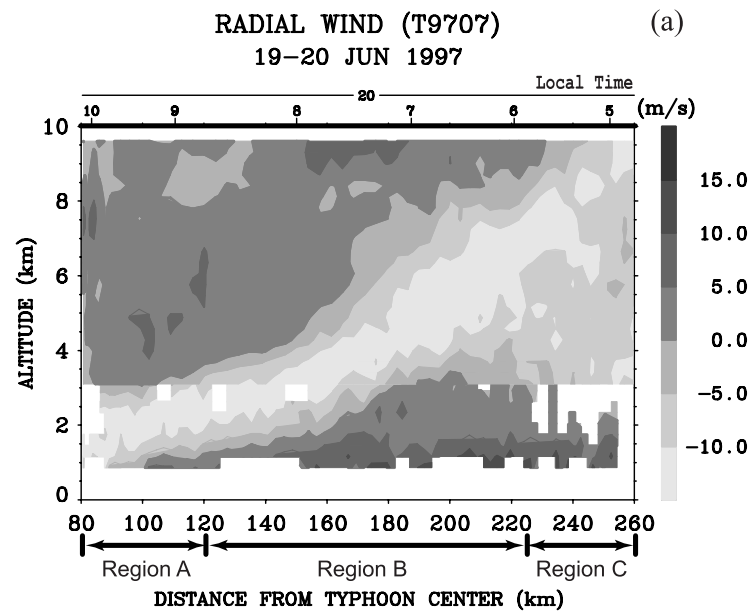

TANGENTIAL WIND (T9707)

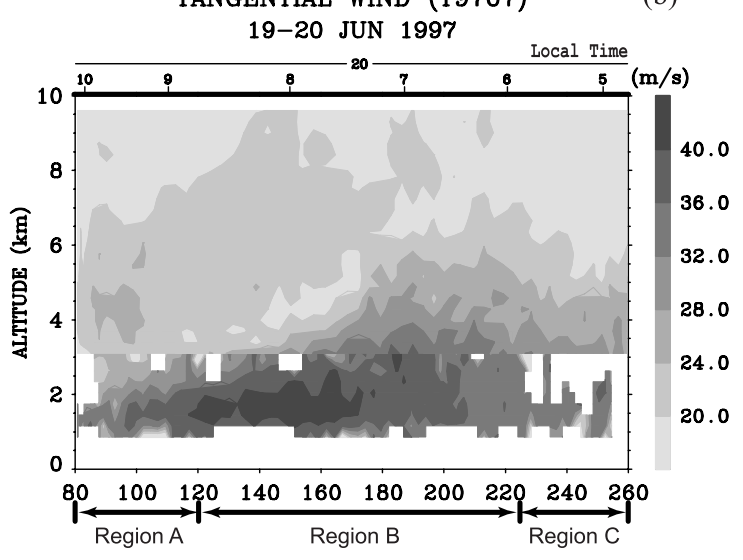

DISTANCE FROM TYPHOON CENTER $(\mathrm{km})$

Fig. 9. Radius-height cross section of (a) radial and (b) tangential winds obtained by the MU radar and the L-band BLR before the passage of the typhoon center at an interval of $6 \mathrm{~min}$. The height interval of the MU radar and the BLR is $150 \mathrm{~m}$ and $100 \mathrm{~m}$, respectively. Positive and negative values of radial wind indicate inflow and outflow, respectively. Positive values of tangential wind indicate counterclockwise winds.

Sato, T., Ao, N., Yamamoto, M., Fukao, S., Tsuda, T., and Kato, S.,A typhoon observed with the MU radar, Mon. Weath. Rev., 119, 755-768, 1991.

Sato, K., Small-scale wind disturbances observed by the MU radar during the passage of Typhoon Kelly, J. Atmos. Sci., 50, 518537, 1993.

Shimazu, Y., Wide slow-moving rainbands and narrow fast-moving rainbands observed in Typhoon 8913, J. Meteor. Soc., Japan, 75, 67-80, 1997. (a)
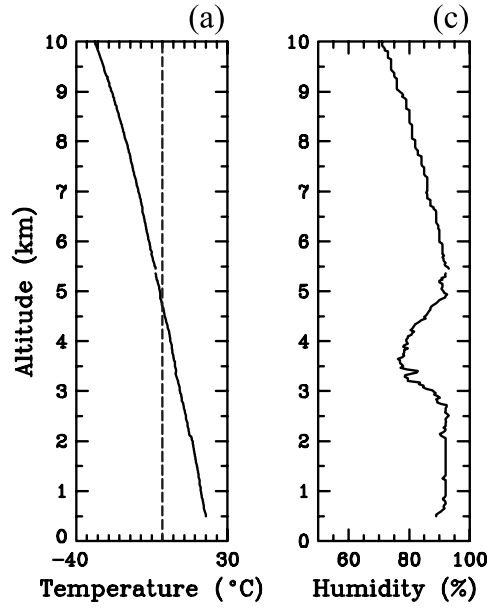

(b)

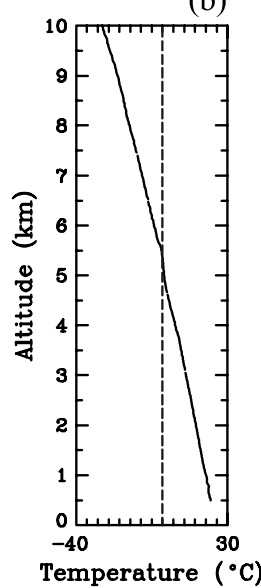

(d)

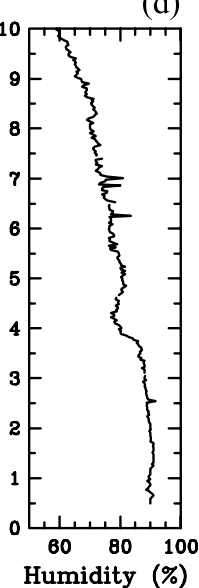

Fig. 10. The profiles of temperature (a) and (b) and relative humidity (c) and (d) observed with radiosondes launched at 0531 LT (upper panels) and 0826 LT (lower panels) on 20 June 1997. The typhoon was located at the distance of about $240 \mathrm{~km}$ and $130 \mathrm{~km}$ from the MU radar site at 0531 and $0826 \mathrm{LT}$, respectively.

Tabata, A., Sakakibara, H., Ishihara, M., Matsuura, K., and Yanagisawa, Z., A general view of the structure of Typhoon $8514 \mathrm{ob}-$ served by dual-Doppler radar -From outer rainbands to eyewall clouds, J. Meteor. Soc. Japan, 70, 897-917, 1992.

Wakasugi, K., Mizutani, A., Matsuo, M., Fukao, S., and Kato, S., A direct method for deriving drop-size distribution and vertical air velocities from VHF Doppler radar spectra, J. Atmos. Oceanic Tech., 3, 623-629, 1986.

Willoughby, H. E., Marks, F. D., Jr., and Feinberg, R. J., Stationary and moving convective bands in Hurricanes, J. Atmos. Sci., 41, 3189-3211, 1984. 